World Maritime University

The Maritime Commons: Digital Repository of the World Maritime University

\title{
Improving governance of maritime higher education institutions to ensure success of filipino cadets
}

Cleto Del Rosario

Dimitrios Dalaklis

Momoko Kitada

Johan Bolmsten

Follow this and additional works at: https://commons.wmu.se/lib_presentations

This Presentation Open Access is brought to you courtesy of Maritime Commons. Open Access items may be downloaded for non-commercial, fair use academic purposes. No items may be hosted on another server or web site without express written permission from the World Maritime University. For more information, please contact library@wmu.se. 


\section{IMPROVING GOVERNANCE OF MARITIME HIGHER EDUCATION INSTITUTIONS TO ENSURE SUCCESS OF FILIPINO CADETS}

Cleto Del Rosario | Dimitrios Dalaklis | Momoko Kitada | Johan Bolmsten World Maritime University (SWEDEN) 


\section{Background}

- Maritime activities have been part of the lives of many Filipinos, considering that the country's archipelagic state.

- There is a great tendency for Filipinos to pursue a maritime career.

- Filipino seafarers infused about US $\$ 5.575$ billion to the country's economy; future projections increase this amount to more than US\$6 billion!

- To maintain the Filipino seafarers responsiveness to the needs of the industry and their global competitiveness, the Philippine Government needs to ensure conformity with the requirements of the Standards of Training, Certification and Watch-keeping (STCW) 1978 Convention and its Amendments.

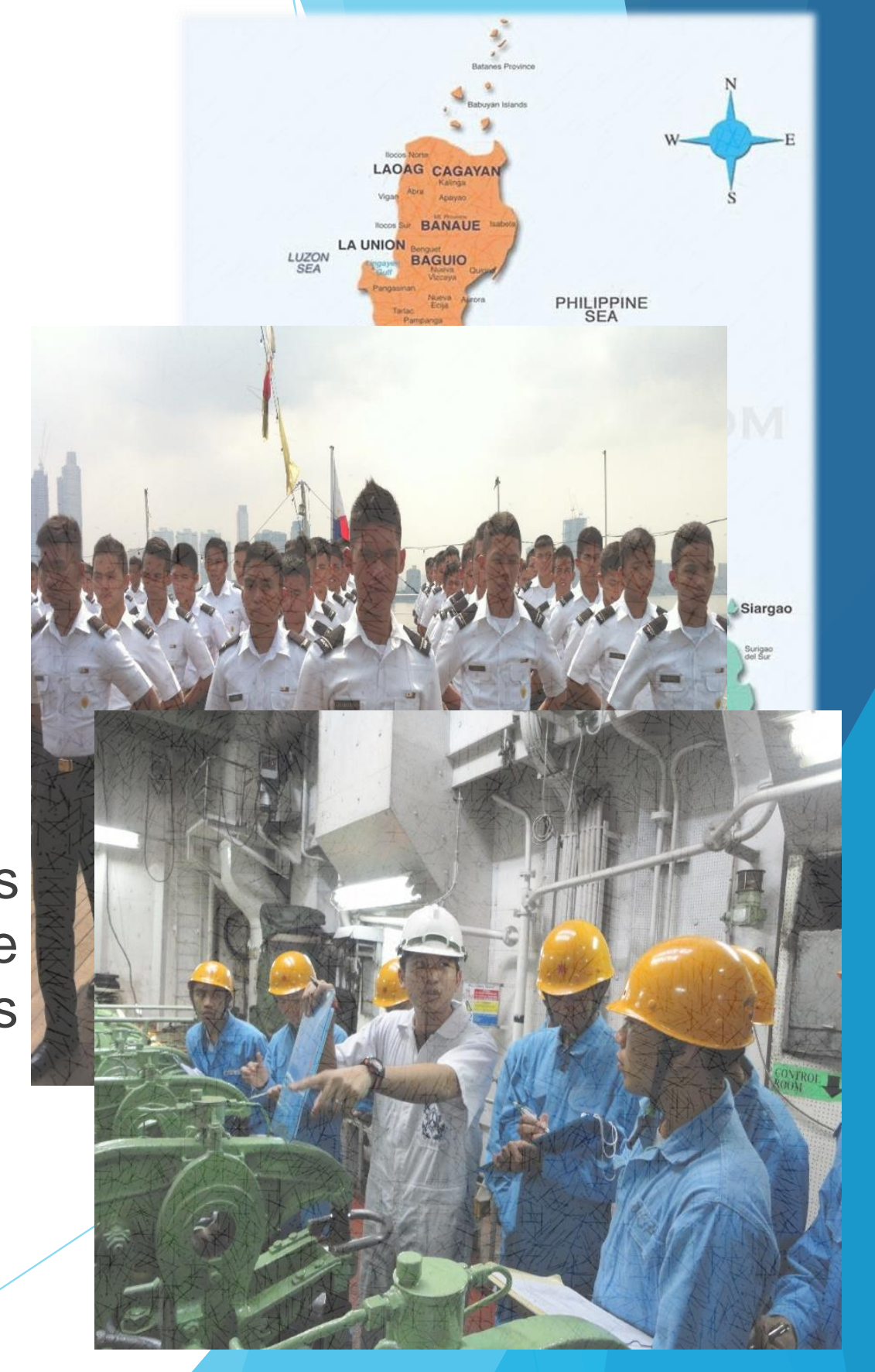




\section{Problem and Study Question}

- The Philippines has a great potential due to the growing number of vacant officer positions on international vessels

- The role of the Philippine Government in ensuring conformity with the requirements STCW 1978 and its Amendments to make the seafarers more responsive to global shipping needs.

- The need to identify the mismatch between governing authorities' policies/expectations and the overall performance of maritime higher education institutions(MHEls)

- The study question is: "How the level of governance is influencing negatively on the success of marine cadets?" 


\section{Maritime Higher Education}

- Bachelor of Science in Marine Transportation (BSMT) or Bacteet of Science in Marine Engineering (BSMarE) programs.

- The three-one (3-1) and the two-one-one (2 - 1 - 1) maritime degree programs.

- There are seventy (70) recognized MHEls in the Philippines.

- AY 2015-2016 there are 124, 438 enrollees in the BSMT and BSMarE programs where 25,855 that qualifies for onboard training, a minir 5,101 or $19.73 \%$ have actually completed the 12 months shipbo training for the completion of their degrees. 


\section{Maritime Higher Education Governing Bodies}

The METIs are governed by three (3) government organizations namely:

D the Maritime Industry Authority (MARINA)

- Commission on Higher Education (CHED)

- and Technical Education and Skills Development Authority (TESDA)

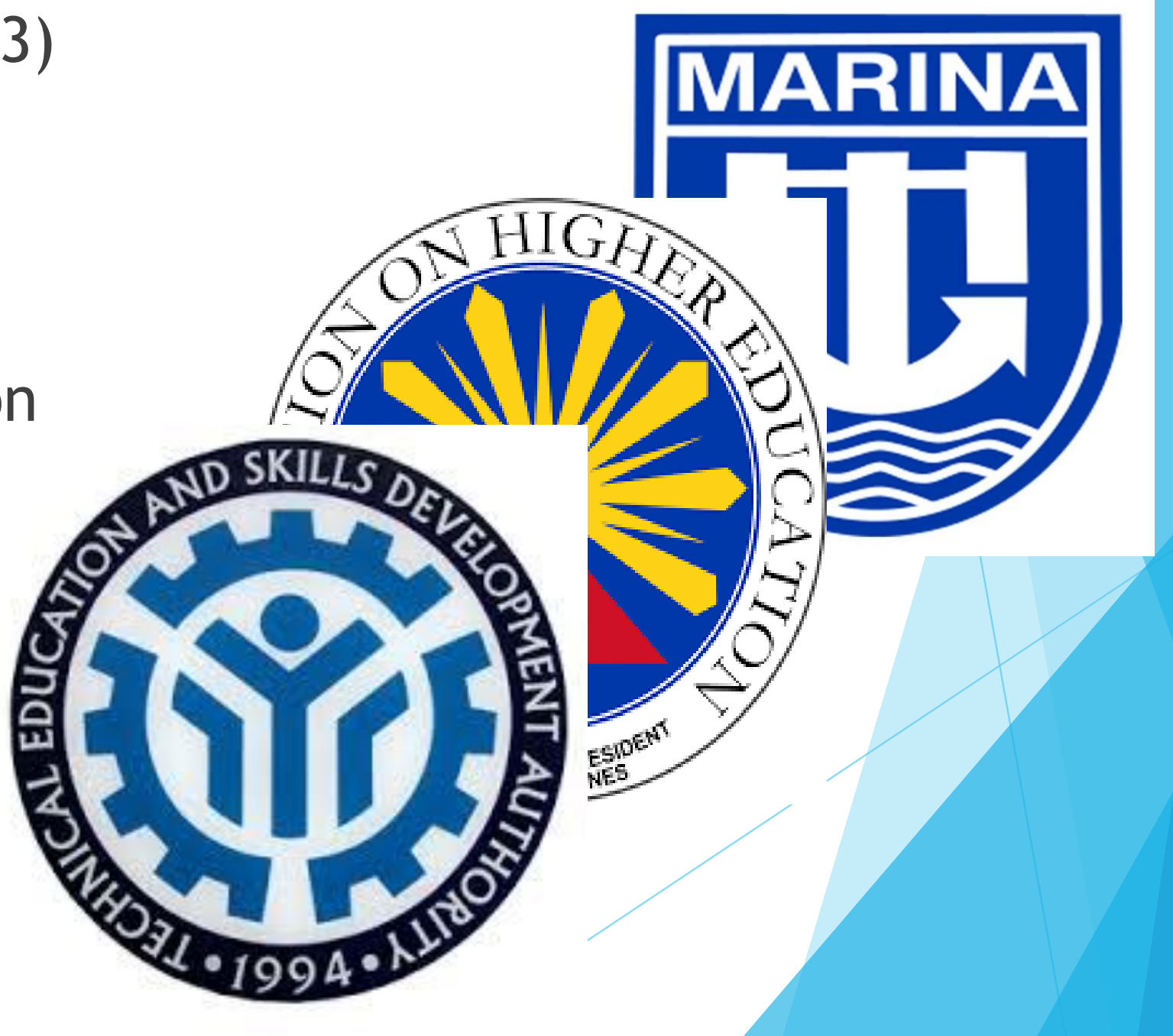




\section{Bureaucratic Theory of Organization}

- Bureaucracy was encapsulated on two (2) forms: "representative" and "punishment" centered. The former was based upon rules and are predicated by trust [1].

- Vladimir Ilych Lenin Ulyanov popularized 'trust is good but control is better' another suggests that 'fear, control, power and corruption are all present in organizations and societies where trust is absent [2].

- In the Philippines, the form is always punishment centered

- Corruption is usually more widespread and deep-rooted in developing countries including the Philippines. 
The Quality Tertiary Education Act of 2017 and the

\section{United Nations Sustainable Development Goals (UNSDGs)}

- The UNSDG Goal 4 evolve on the principle that education is a fundamental human right and an enabling right.

- The Universal Access to Quality Tertiary Education Act of 2017 which declares "that higher education is an alienable rights of every of every Filipinos.

- the law will incrementally improve enrollment rates and will help ease up financial needs of students

(n)
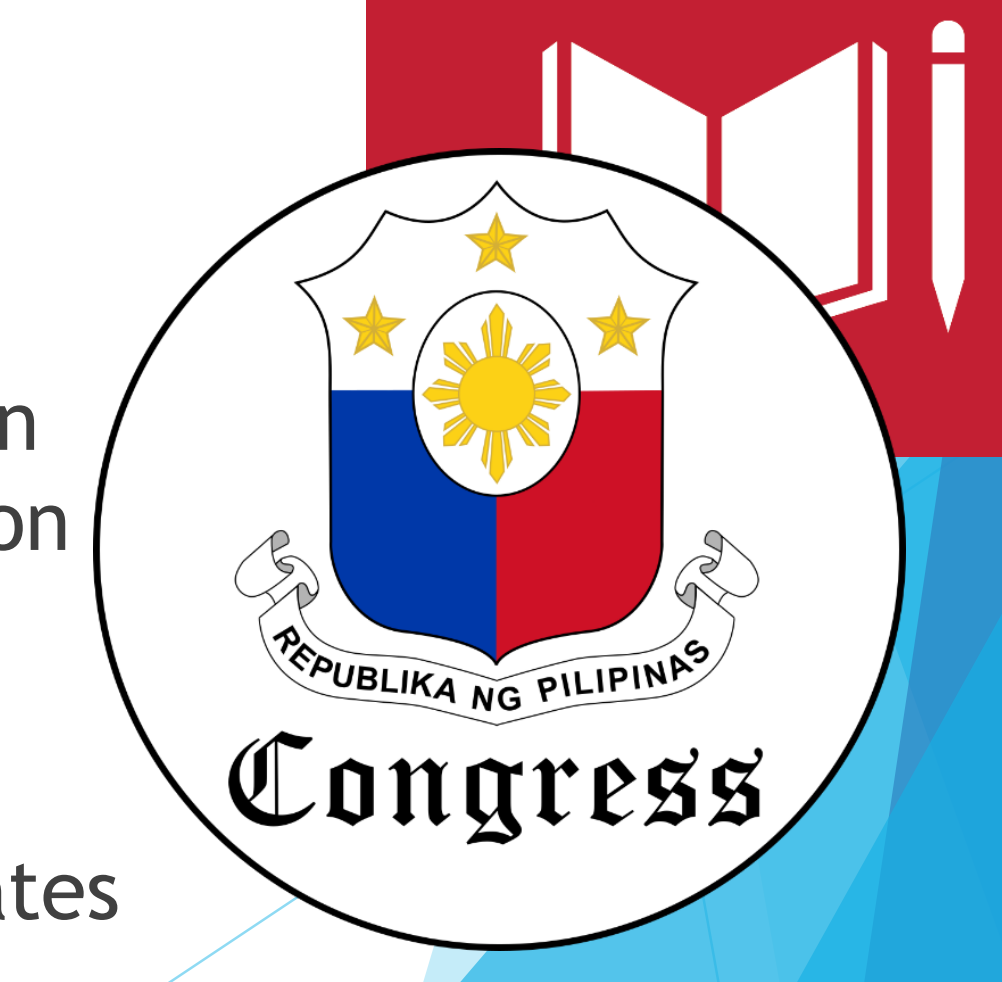


\section{Methods}

- The proposal adopted a quantitative approach.

- Request for records was made to CHED regional offices and central office.

- Secondary data was also obtained from the CHED-Knowledge Management Division.

- Eight regional offices representing 53 MHEls responded to the request

- Figures were counted and tabulated

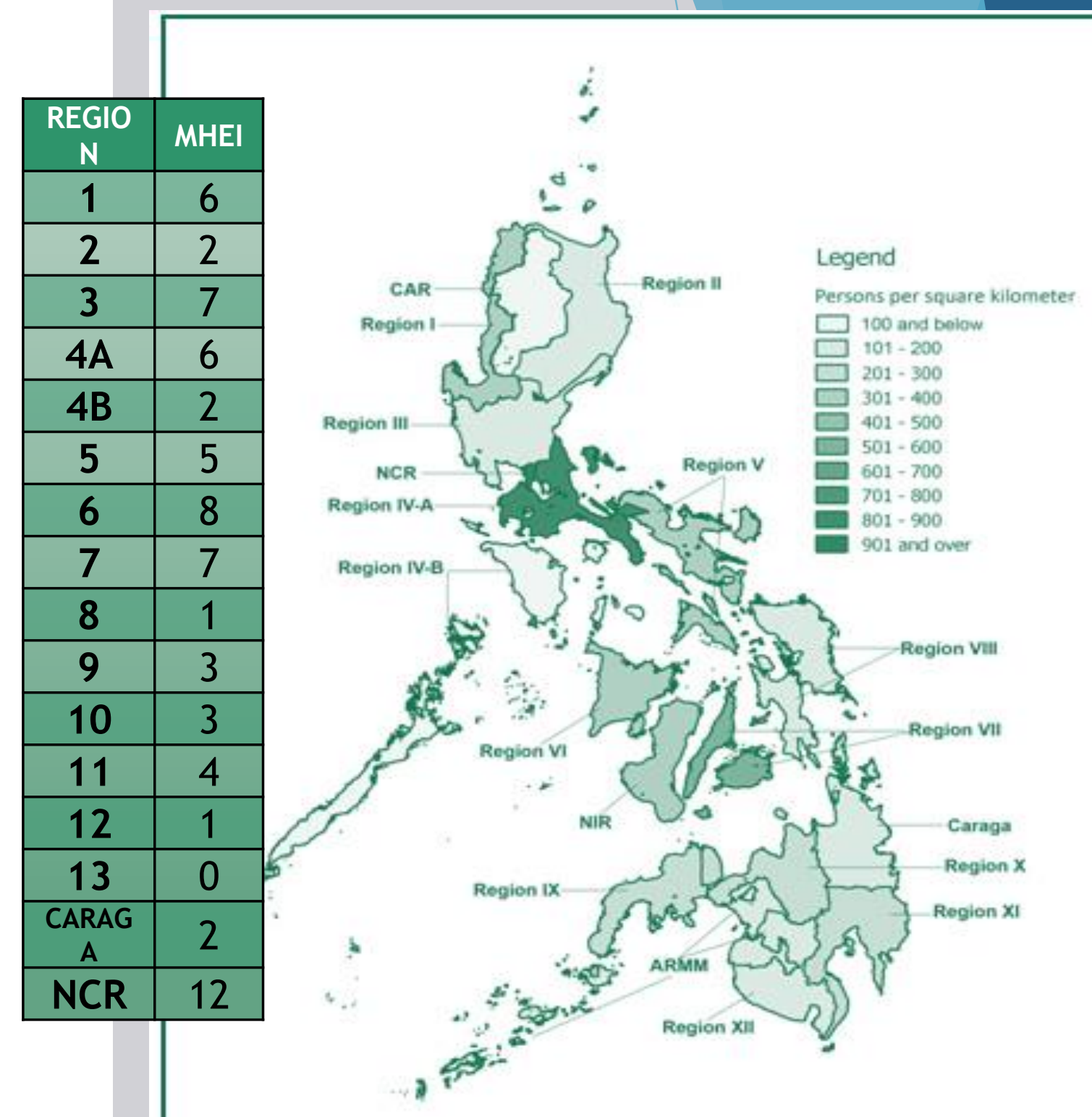




\section{RESULTS}

- For the SY $2017-2018$, Table 1 presents that only 13,835 or $35 \%$ of the 39,012 students who completed courses for onboard training managed to board vessel and eventually graduated. The figure shows that the chance of success in maritime higher education remains scarce.

\begin{tabular}{|l|c|c|c|c|c|}
\hline \multirow{2}{*}{ Program } & \multirow{2}{*}{$3^{\text {rd }}$ year level } & \multirow{2}{*}{\begin{tabular}{c} 
Competed \\
Courses for \\
Onboard \\
\cline { 4 - 6 }
\end{tabular}} & & \multicolumn{3}{|c|}{ Graduates } \\
\cline { 4 - 6 } & & 29,580 & 2761 & 16,129 & 13835 \\
\hline
\end{tabular}

Table 1: Philippine MHEI graduates for S.Y. 2017-2018

Source: Authors' analysis based on the data from the Commission on Higher Education (CHED)) 


\section{Cont.: Results}

\begin{tabular}{|c|c|c|c|}
\hline Region & Enrollment & Graduates & $\begin{array}{c}\text { Success } \\
\text { rates }\end{array}$ \\
\hline I & 7304 & 740 & $10 \%$ \\
\hline II & 1708 & 318 & $19 \%$ \\
\hline III & 5693 & 1094 & $19 \%$ \\
\hline IV-A & 5941 & 832 & $14 \%$ \\
\hline IV-B & 904 & 46 & $5 \%$ \\
\hline V & 3347 & 636 & $19 \%$ \\
\hline VI & 12330 & 2685 & $22 \%$ \\
\hline VII & 18271 & 3780 & $21 \%$ \\
\hline VIII & 1054 & 426 & $40 \%$ \\
\hline IX & 2266 & 743 & $33 \%$ \\
\hline X & 2113 & 557 & $26 \%$ \\
\hline XI & 3940 & 410 & $10 \%$ \\
\hline XII & 1623 & 418 & $26 \%$ \\
\hline XIII & 744 & 217 & $29 \%$ \\
\hline NCR & 13550 & 933 & $7 \%$ \\
\hline Total & 80,788 & 13835 & $17 \%$ \\
\hline
\end{tabular}

- Data reveals the success rate of MHEls is only $17 \%$ throughout the Philippines. This means that only $17 \%$ of marine cadets shall have an embarkation opportunity and ultimately work onboard the ship as a seafarer.

- Figures per region reveal that the success does not depend with the number of enrollments, but on other factors that can be discovered as the study progresses further.

Table 2: Philippine MHEI success rates by region for S. Y. 2017-2018

(Source: Authors' analysis based on the data from Commission on Higher Education, Central and Regional Offices) 


\section{Cont.: Results}

\begin{tabular}{|c|c|c|c|}
\hline Region & $\begin{array}{c}\text { Employment } \\
\text { Rates }\end{array}$ & Graduates & Success rates \\
\hline I & $93.2 / 61.7$ & 740 & $10 \%$ \\
\hline II & $97.0 / 63.9$ & 318 & $19 \%$ \\
\hline III & $94.2 / 59.9$ & 1094 & $19 \%$ \\
\hline IV-A & $93.4 / 62.7$ & 832 & $14 \%$ \\
\hline IV-B & $95.3 / 62.0$ & 46 & $5 \%$ \\
\hline V & $95.1 / 60.9$ & 636 & $19 \%$ \\
\hline VI & $94.7 / 61.2$ & 2685 & $22 \%$ \\
\hline VII & $94.7 / 61.3$ & 3780 & $21 \%$ \\
\hline VIII & $95.8 / 61.2$ & 426 & $40 \%$ \\
\hline IX & $95.9 / 56.3$ & 743 & $33 \%$ \\
\hline X & $95.9 / 66.3$ & 557 & $26 \%$ \\
\hline XI & $95.7 / 60.3$ & 410 & $10 \%$ \\
\hline XII & $96.1 / 61.7$ & 418 & $26 \%$ \\
\hline XIII & $96.0 / 64.4$ & 217 & $29 \%$ \\
\hline NCR & $93.4 / 60.3$ & 933 & $7 \%$ \\
\hline CARAGA & $95.9 / 61.9$ & & \\
\hline ARMM & $96.3 / 46.6$ & & \\
\hline I. Phil & & \\
\hline
\end{tabular}

- Can be partially construed that the maritime profession is being viewed by the populace as either source of labor.

- Maritime profession is not popular to places where labor participation rate is low like the Autonomous Region of Muslim Mindanao (ARMM) and the Cordillera Autonomous Region (CAR) which is landlocked and also no $\mathrm{MHEl}$ is in place.

Table 3: Philippine unemployment rates and MHEI success rates by region (Source: Authors' analysis based on the data from CHED, Central and Regional Offices and Regional Employment Rates.) 


\section{Conclusion}

- Global shipping contributes to social and economic development of the Philippines.

- Opportunities are still ripe for more deployment due to deficiency in the world supply of competent seafarers.

- Marina is vested with all administrative and legal authority to oversight the increase in the success rate of maritime cadets.

- The governance system that MARINA implements needs to be reviewed taking into consideration SDG 4 and Quality Tertiary Education Act 2017.

- Further studies should be conducted to delve into this situation more deeply. 
Thank you 